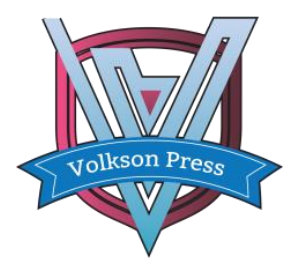

Contents List available at VOLKSON PRESS

Engineering \& Technology Innovations (ETI)

DOI : http://doi.org/10.26480/iceti.01.2017.155.158

\title{
Research Status \& Development Trend of Digital Health Monitoring of Architectural Heritage
}

Gao Chao ${ }^{\mathrm{a}}$, Wang Guoli*ab, Wang Yanmin ${ }^{\text {ab }}$, Zhao Jianghongab

${ }^{a}$ School of Geomatics and Urban Information, Beijing University of Civil Engineering and Architecture,15 Yongyuan Road, Daxing District, Beijing,102616, China

${ }^{b}$ Beijing Key Laboratory For Architectural Heritage Fine Reconstruction \& Health Monitoring, Beijing ,102616, China

${ }^{*}$ Corresponding Author: Wangguoli@bucea.edu.cn

This is an open access article distributed under the Creative Commons Attribution License, which permits unrestricted use, distribution, and reproduction in any medium, provided the original work is properly cited

\section{ARTICLE DETAILS}

\section{Article History:}

Received 02 october 2017 Accepted 06 october 2017 Available online 11 october 2017

\section{Keywords:}

Architectural heritage protection, Health monitoring, Terrestrial LiDAR, Photogrammetry, Remote sensing.

\section{ABSTRACT}

Digital Heritage monitoring is of great importance in the preventive protection of architectural heritage. The most popular technical methods in current digital monitoring of construction heritage are including: traditional measurement technology, 3D laser scanning technology, photogrammetry technology and so on. This paper summarizes various domestic and foreign digital devices, monitoring objects and indexes by reviewing the relevant literatures on the digital health monitoring of architectural heritage. Moreover, by comparing the characteristics of several technical methods, application objects and the achievement accuracy, this paper combing the domestic and foreign application situation of the technology and the monitoring objectives appeared in typical cases, points out the characteristics of various methods and the problems that may be faced by the current construction heritage monitoring.

\section{INTRODUCTION}

Historical architecture is a large, intuitive, vivid history book that exists in the environment, and the architectural heritage is rich of cultural memory. In China, with the "inscription" enthusiasm, there are totally 29 cultural heritage listed on the "World Heritage List" till now, including Great Wall, Mogao Grottoes, the National Palace Museum and others.

With the development of digital technology, digital heritage around the world is growing rapidly, in the field of architectural heritage digitization, domestic scholars in ancient buildings, caves, a number of construction sites such as the content of research work has been carried out a series of digital cultural heritage protection. These different digital methods in object, characteristics, process, there are differences in achievement and accuracy, understand the characteristics of these techniques has important reference value to the architectural heritage of the next step of health monitoring development and technology integration.

This paper will focus on ways for architectural heritage and digital monitoring at home and abroad this paper makes comparative analysis of different means of monitoring objects and damage categories applicable, provide effective reference for architectural heritage and health monitoring, problems and development trend of the digital methods were put forward.

\section{Architectural heritage digital health monitoring}

Health monitoring of architectural heritage is similar to human health examination, through regular monitoring work, can timely find architectural heritage in some buildings such as settlement, weathering, damage and the others. The monitoring object is what we need to collect the information in monitoring work for, the contents can be divided into the health monitoring for the architectural heritage itself and the surrounding natural .There are different diseases in the monitoring objects of different building types, and the main factors that constitute the disease are different. The annual report of Chinese Cultural Heritage Monitoring in 2014 already give us a summary of the main damage for the several typical buildings:
Table 1. Monitoring object and its main damage

\begin{tabular}{lll}
\hline Monitoring object & \multicolumn{2}{c}{ Main damage } \\
\hline & $\begin{array}{l}\text { Wooden frame } \\
\text { building }\end{array}$ & Pest,crack,deflection,uneven sedimentation \\
\cline { 2 - 4 } & Tower buildings & Torsion, tilt \\
\cline { 2 - 4 } $\begin{array}{l}\text { Geometric } \\
\text { Monitoring }\end{array}$ & $\begin{array}{l}\text { Inscriptions and } \\
\text { sculptures }\end{array}$ & $\begin{array}{l}\text { Cracking, surface peeling, surface dust } \\
\text { attachment and other man-made damage }\end{array}$ \\
\cline { 2 - 4 } & $\begin{array}{l}\text { Large-scale } \\
\text { heritage }\end{array}$ & Rock stability, collapse, seepage, fracture, mold \\
\cline { 2 - 4 } & $\begin{array}{l}\text { Natural } \\
\text { environment }\end{array}$ & Surrounding vegetation, water, climate \\
\cline { 2 - 4 } $\begin{array}{l}\text { Environment } \\
\text { Monitoring }\end{array}$ & $\begin{array}{l}\text { Social } \\
\text { environment }\end{array}$ & $\begin{array}{l}\text { Protection scope and control zone, visitor } \\
\text { capacity }\end{array}$ \\
\hline
\end{tabular}

\section{Digital monitoring}

The digital monitoring of architectural heritage includes Traditional measurement technology, 3D laser scanning, photogrammetry and other technical means. The following will be based on these technical tools combined with the actual case study.

\subsection{Convetional methods}

Traditional data acquisition methods are mostly single-point access. The common technology in traditional measurement includes leveling instrument, total station and GNSS.The traditional measurement technology can be used in the building monitoring, mainly through the regular observation of the height of the fixed point elevation to get the settlement law of the building. Li Qiuying used the DINI03 digital level for 14 months occurrence sites on the soil foundation, finally obtained the cumulative subsidence quantity is $0.7 \mathrm{~mm}$, indicating that the site has increased slightly. 
Abed used total station and GPS to assist in monitoring the deflections and cracks of the Minaret. The tower is measured in three parts as shown in figure 1.

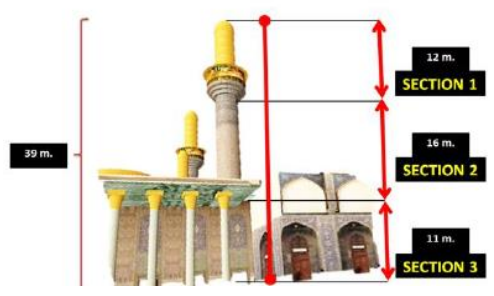

Figure 1. Minarets' measurements sections

It was found that the deflection magnitude increased between May 2014 and January 2015, these values have remained stable since January 2015.

\section{$3.2 \quad$ Terrestrial laser scanning technology(TLS)}

TLS is mainly used in the surface damage and structural safety monitoring. 3.2.1. Surface damage monitoring of architectural heritage

For protecting Grottoes, Yungang Grottoes Research Institute used a variety of types of terrestrial laser scanner to obtain the multi-level precision point cloud model.

Table 2. 3D laser scanner and its scanning position

\begin{tabular}{lll}
\hline Type & Accuracy & Scanning position \\
\hline surphrser & $0.3 \mathrm{~mm}$ & Part of the inner walls of the grotto; \\
Leica ScanStation 2 & $4-6 \mathrm{~mm}$ & The whole external walls \\
Handheld scanner & $0.03 \mathrm{~mm}$ & Details and inconvenient space \\
\hline
\end{tabular}

The final products is ortho-photo maps obtained by textured TIN model, which can reach millimeter or sub-millimeter. It can fully reflect all the small changes of grottoes.
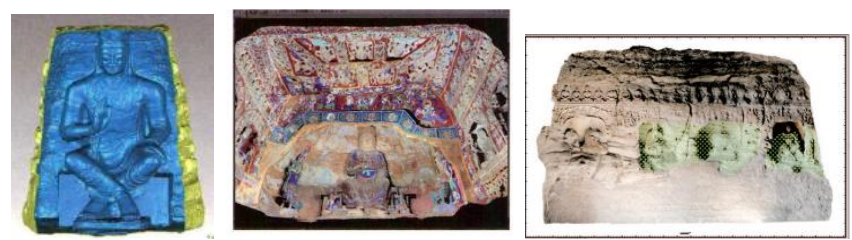

Figure 2. TIN model、color point cloud、grotto damage (Lu Jiwen, 2016)

Wu Yuhua(2011) used TLS to make a comprehensive monitoring for its surface morphology of No. $9 \& 10$ Grottoes to get cracking trend of rock pillar.

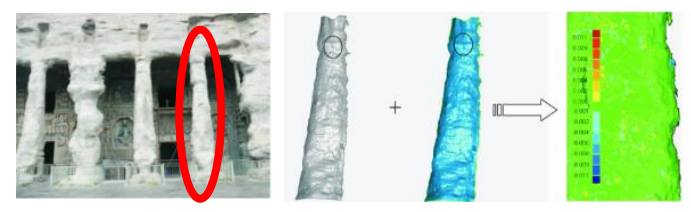

Figure 3. Yungang Grottoes $9 \& 10$ cave and two period data comparison

\subsubsection{Architectural heritage deformation monitoring}

On the basis of TLS point cloud for the ancient building, the overall deformation and local structural damage of the ancient building are analyzed by modeling and cutting.

Wang Yanmin(2010) analyzed the deformation of Multi-Door Chorten in Baiju Temple in 2008 and 2010 and founded the maximum change of the tower is $0.7 \mathrm{~cm}$ and the maximum change of the five layers of the roof axis in the north-south direction is about $11.6 \mathrm{~cm}$.

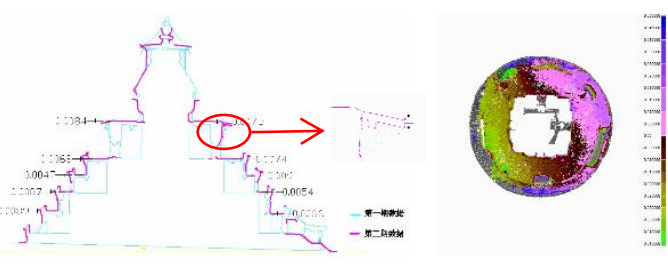

Figure 4. Deformation analysis, deformation analysis of the fifth story roof

Bonlali used the 3D laser scanning point cloud to the cantalovo church wall facade fitting plane as a reference face alignment point cloud data analysis in April 2011 and June 2012, the overall deformation and evolution trend from the $\mathrm{cm}$ level precision analysis showed that after the church facade, the temple serious deformation, the biggest difference between $3-4 \mathrm{~cm}$ (Figure $5(d)$ ) .

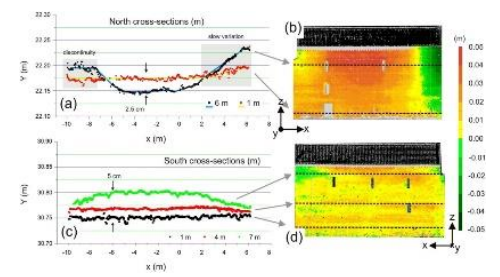

Figure 5. (a, c) for the north south elevation profile, $(b, d)$ for the overall deformation trend

\subsection{Photogrammetry technology}

Low altitude and close-range photogrammetry can obtain the object shape, size, location, characteristics of heritages by 3D reconstruction from sequence images.

\subsubsection{Low altitude photogrammetry}

Risbøl analyzed the changes of existing environmental heritage the influence of Mecocci DEM data through the identification of ALS the changes of environment and combining with historical aerial photographs in different years the extracted and ALS of Mølen Pebble Beach surrounding natural environment are investigated.

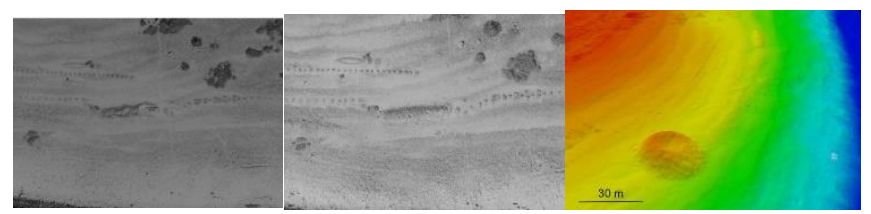

Figure 6. 1979, 1999 aerial images, DTM generation of ALS in 2010

According to the data, the difference model of the 1968-2010 time interval is obtained, which indicates that the red area has increased since 1968, and other indicate decreasing area.

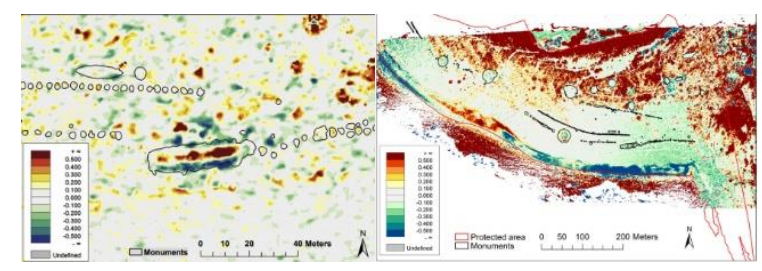

Figure 7. 1979-1999 difference model , 1968-2010 search model

Li Zhe obtained the complete surface data of Dule Temple Pagoda with UAV photogrammetry, the 3D point cloud generated with sub millimeter point density and relative measuring accuracy. According to the multi slice dissection and centroid calculation, the overall deflection data of the ancient pagoda axis eccentricity is obtained. The tower body bulging and other diseases of 3D model analysis were made on the tower(10.5m high) by Point cloud Compare. 


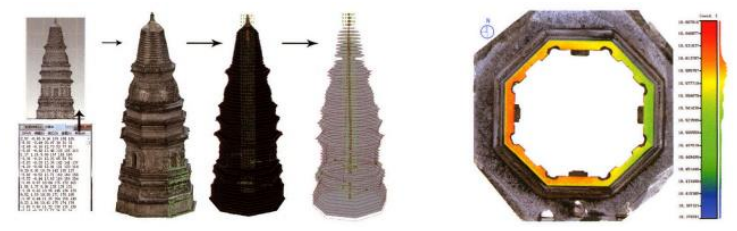

Figure 8. 3D model and sketch of horizontal cutting and Plane level pseudo color diagram

UAV has advantages in data acquisition for high-rise buildings and large ancient ruins.

\subsubsection{Close-range photogrammetry}

TLS can't provide enough data to construct the contours of all surface features of scanned objects, and Close-range photogrammetry compensates this defect.

Alshawabkeh(2006) extracted 3D feature of the gate ( Petra's monument data from the Al-Khasneh survey), which contain clear edges and linear surface feature contours.
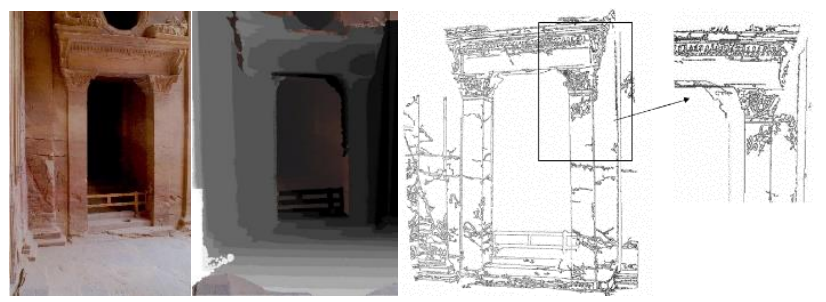

Figure 9. The left door $\&$ the distance projection image and the feature extraction

Li Yan(2010) used the digital close range photogrammetry to measure the inside and outside of the Purple bamboo Church in Tianjin, and get the elevation and plan of the building.

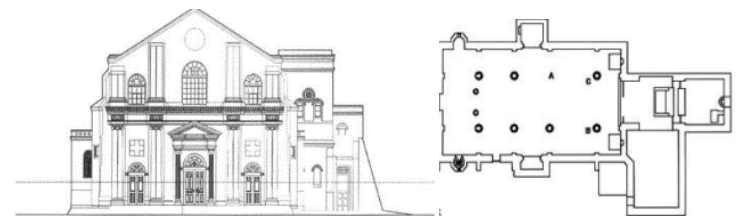

Figure 10. Purple bamboo Church elevation and plan

Photogrammetry technology is suitable for the surface features of large architectural heritage, this method is more flexible, wider scope of data collection. The introduction of photogrammetry technology makes more and more precision of architectural detail is high, the work efficiency is significantly improved.

\section{Conclusion}

Now the architectural heritage monitoring technology system has formed a variety of technical means to support each other, through the above analysis of literature combination of heritage protection and development trend, at present in the field of architectural heritage health monitoring there are some typical problems, specifically as follow:

1) The monitoring method and data processing of architectural heritage mainly rely on artificial, low degree of automation. Future research should focus on how to use scientific methods to improve monitoring efficiency.

2) The digital results of various types of lack of unified management, comparative analysis platform, data sharing difficult.

3) Lack of standardization heritage monitoring technology, institutional mechanism is not perfect, the lack of monitoring and warning level standard.

\section{Acknowledgment}

This paper was founded by Funding for Natural Science of Beijing (4144071) ; Science and technology development plan For Beijing Municipal Education Commission (KM201510016016).

\section{References}

[1] Abed, F. M. (2015). Terrestrial laser scanning to preserve cultural heritage in Iraq using monitoring techniques.

[2] Al-Kheder, S., Al-Shawabkeh, Y., \& Haala, N. (2009). Developing a documentation system for desert palaces in jordan using $3 \mathrm{~d}$ laser scanning and digital photogrammetry. Journal of Archaeological Science,36(2), 537546.

[3] Alshawabkeh, Y., \& Haala, N. (2006). Integration of laser scanning and photogrammetry for heritage documentation. Uni Stuttgart Universitätsbibliothek.

[4] Beg, M. S. (2016). Issues of conservation and adaptation in protecting kashmir's vernacular heritage. International Journal of Environmental Studies, 1-9.

[5] Bonali, E., Pesci, A., Casula, G., \& Boschi, E. (2014). Deformation of ancient buildings inferred by terrestrial laser scanning methodology: the cantalovo church case study (northern italy)*. Archaeometry, 56(4), 703716.

[6] Bujakiewicz, A., Markiewicz, J., Bakuła, K., \& Zawierska, D. (2014). Diversity of photogrammetric approaches for multi-purpose applications.Reports on Geodesy \& Geoinformatics, 96(1), 9-19.

[7] Bu Lin. (2012) research on exhibition system of Chinese Cultural Heritage (Doctoral dissertation, Northwestern University)

[8] Fonte, J. (2014). Using airborne laser scanning and historical aerial photos to identify modern age fortifications in the Minho Valley, Northwest Iberian Peninsula. The Three Dimensions of Archaeology, Proceedings of the XVII UISPP World Congress (1-7 September, Burgos, Spain). Volume 7/Sessions A4b and A12.

[9] Li Qiuying, Zhou Junzhao, Xia Guofang, Xue Tianzong, Ding \& fourth. (2013). Soil site comprehensive monitoring technique and its application in engineering survey, 41 (11), 63-66.

[10] Li Yan, Li Zhe, \& Zhang Yukun. (2010) architectural photogrammetry system and its application case. New architecture (5), 130-135.

[11] Li Zhe, Zhou Cheng legend, Yan Yu, \& Liu Yu. (2016). Photogrammetry and 3D data processing application in surveying and mapping brick tower in Tianjin -- Taking dule temple tower as an example. Chinese low cultural heritage (3).

[12] Lu Jiwen, \& Ningbo. (2016) digital exploration and practice of cultural relics in Yungang Grottoes. Research on heritage and protection, 1 (2), 1114.

[13] Moussa, W. (2014). Integration of digital photogrammetry and terrestrial laser scanning for cultural heritage data recording. Uni Stuttgart - Universit鋞sbibliothek.

[14] Reis, G., \& Stricker, D. (2015). Fully automatic, omnidirectional acquisition of geometry and appearance in the context of cultural heritage preservation. Journal on Computing \& Cultural Heritage, 8(1), 2.

[15] Risbøl , O., Briese, C., Doneus, M., \& Nesbakken, A. (2015). Monitoring cultural heritage by

[16] comparing dems derived from historical aerial photographs and airborne laser scanning.Journal of Cultural Heritage,16(2), 202-209.

[17] Rüther, H., Chazan, M., Schroeder, R., Neeser, R., Held, C., \& Walker, S. J., et al. (2009). Laser scanning for conservation and research of african cultural heritage sites: the case study of wonderwerk cave, south africa. Journal of Archaeological Science, 36(9), 1847-1856.

[18] Schueremans, L., \& Genechten, B. V. (2009). The use of 3d-laser scanning in assessing the safety of masonry vaults-a case study on the church of saint-jacobs. Optics \& Lasers in Engineering, 47(3), 329-335.

[19] Tang Qin (2016). Status and Enlightenment of application of 3D laser scanning technology in the world. Nonferrous metals in the world (12), 2123.

[20] Wang Yanmin, Huo Hui, Wang Guoli, \& Hu Chunmei (2011). The ground laser radar technology application in analysis of deformation palkor auspicious than tower. Journal of Beijing Institute of Civil Engineering and Architecture, 27 (4), 11-15. 
[21] Wu Yuhua, Hou well, \& Zhang Yumin. (2011). In the progress of application in rock and soil conservation and the direction of the 3 dimensional laser scanning technology. The geographic information world, 09 (2), 53-57.
[22] Zhou Shiju. (2016) the protection of Yungang Grottoes Cultural Heritage Based on digital ideas and methods. Journal of Shanxi Normal University (NATURAL SCIENCE EDITION) (2), 108-111. 